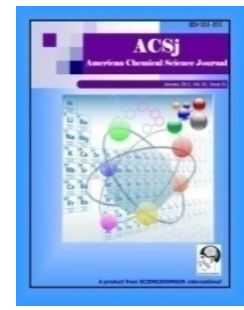

American Chemical Science Journal

2(4): 122-135, 2012

SCIENCEDOMAIN international

www.sciencedomain.org

\title{
Corrosion Inhibition of Aluminium in Acidic Medium by Different Extracts of Ocimum gratissimum
}

\author{
I. J. Alinnor ${ }^{1^{\star}}$ and P. M. Ejikeme ${ }^{2}$ \\ ${ }^{1}$ Department of Pure and Industrial Chemistry, Federal University of Technology, P.M.B. \\ 1526, Owerri, Imo State, Nigeria. \\ ${ }^{2}$ Department of Pure and Industrial Chemistry, University of Nigeria, Nsukka, Enugu State,
}

Nigeria.

\section{Authors' contributions}

This work was carried out in collaboration between the authors. Author IJA designed the study, performed the graphics and tables, wrote the first protocol, wrote the first manuscript. Author PME managed the analysis of the study and literature research. All authors read and approved the final manuscript.

Research Article

Received $18^{\text {th }}$ July 2012 Accepted $16^{\text {th }}$ October 2012 Published $20^{\text {th }}$ November 2012

\section{ABSTRACT}

Aims: This study is aimed at using plant extracts to prevent corrosion of aluminium in acidic medium. The inhibition efficiency of different extracts of $1 \mathrm{M} \mathrm{HCl}$, ethanol and distilled water were determined.

Study Design: Gravimetric method was used for the analysis.

Place and Duration of Study: Department of Chemistry, Federal University of Technology, Owerri, Nigeria, between March and November, 2011.

Methodology: Aluminium sheets of AA1060 and purity $98.98 \%$ was used. Each sheet was mechanically press-cut into coupons of dimension $3 \mathrm{~cm} \times 3 \mathrm{~cm}$. The solvents used for extraction of ocimum gratissimum leaf were $1 \mathrm{M} \mathrm{HCl}$, ethanol and distilled water, respectively. A hole with diameter $0.5 \mathrm{~cm}$ was drilled in each aluminium coupon and suspended in beakers containing test solution using glass hook. The weight loss was determined by retrieving coupons from test solutions at intervals. The coupons were weighed after retrieving. The different in weight was taken as weight loss of aluminium. 
Results: The percentage of inhibition efficiency (\% I.E) was calculated at $303 \mathrm{~K}$ and 333 $\mathrm{K}$, respectively. The result indicates that \% I.E increases as concentration of inhibitor increases. The trend of inhibition efficiency was in order: Distilled $\mathrm{H}_{2} \mathrm{O}>\mathrm{C}_{2} \mathrm{H}_{5} \mathrm{OH}>1 \mathrm{M}$ $\mathrm{HCl}$. The result indicates that increase in temperature decreases inhibition efficiency and degree of surface coverage. The result shows that apparent activation energy $E_{a}$ increases as inhibitor concentration increases. The activation energy of distilled water extract range between 45.02 to $79.90 \mathrm{~kJ} / \mathrm{mol}$. While the activation energies of ethanol and $1 \mathrm{M} \mathrm{HCl}$ extracts of the inhibitor ranges between 35.12 to $72.93 \mathrm{~kJ} / \mathrm{mol}$ and 26.60 to $65.25 \mathrm{~kJ} / \mathrm{mol}$, respectively. The experimental data obtained corroborated with Langmuir and Flory Huggins adsorption isotherms.

Conclusion: This study indicates that different extracts of Ocimum gratissimum inhibits aluminium surface in presence of $1 \mathrm{M} \mathrm{HCl}$. The result of the analysis shows that inhibition efficiency and degree of surface coverage decreases as temperature increases. The activation energy of different extracts increases as concentration of inhibitor increases. The negative values of $\Delta G_{a d s}$ shows that adsorption of inhibitor on surface of aluminium is spontaneous.

Keywords: Acid corrosion; weight loss; aluminium; adsorption; Ocimum gratissimum.

\section{INTRODUCTION}

Aluminium is a hard, strong, white metal. It is highly electropositive and resistant to corrosion because a hard, tough film of oxide is formed on the surface (Cotton and Wilkinson, 1972). The surface film is amphoteric, hence the metal could dissolve readily in both strong acid and alkaline media. Hydrochloric acid solutions are normally used for pickling of aluminium and electrochemical etching processes that normally lead to substantial loss of metal to corrosion. Aluminium is extensively used in industry as well as domestic applications.

Attempts have been made to reduce aluminium surface film dissolution and hence protect the metal in aggressive acid and alkaline media. Some of the methods employed to reduce corrosion of aluminium is application of sulphur, oxygen or nitrogen containing organic compounds as corrosion inhibitors to hinder corrosion reaction and thus reduce corrosion rate (Moussa et al., 1998; Madkour et al., 1999; Ebenso et al., 2001; Aytac et al., 2005). These organic compounds function by forming a protective adsorption layer on aluminium surface which isolates the corroding metal from action of corrodent.

Corrosion behaviour of aluminium has been studied in acid media. It has been reported that addition of halide salt to sulphuric acid solution containing organic inhibitor, effectively inhibits iron corrosion (Oguzie et al., 2004; Elewady et al., 2008). Halides have been reported to inhibit corrosion of some metals in strong acids and this effect depends on ionic size and charge. The use of chemical inhibitors has been a concern about its toxicity which affects the living organism as well as poisoning of environment. The use of plant extracts to prevent corrosion has become important because they are environmentally acceptable, readily available and renewable source for a wide range of inhibitors. Plant extracts are rich source of naturally synthesized chemical compounds that can be extracted by simple methods with low cost (Abdel-Gaber et al., 2008). These extracts are biodegradable and do not contain heavy metals or other toxic compounds. The use of plant extracts as corrosion inhibitor of metals in acidic and alkaline media have been reported (Abiola et al., 2007; Kliskic et al., 2000; Umoren and Ebenso, 2008; Oguzie, 2005; Eddy and Ebenso, 2008). 
Ocimum gratissimum (scent leaf) is widely distributed in tropical Africa especially Nigeria. It belongs to lamiacea family and most abundant of genus Ocimum. The Igbos of Eastern part of Nigeria calls it Nchonwu. The Yorubas of Western part of Nigeria calls it Efinrin ajase, whereas Hausas of Northern part of Nigeria call it Daidoya (USDA, 2008). It is a perennial plant and woody at base. It has an average height of 1-3 m high and leaves are broad, narrowly ovate, usually $5-13 \mathrm{~cm}$ long and $3-9 \mathrm{~cm}$ wide. It is scented shrub with lime-green fuzzy leaves. It is used in Nigeria for nutritional and therapeutic purposes. In coastal area of Nigeria it is used for treatment of epilepsy, high fever and diarrhea, while in savannah areas, decoctions of its leaves are used to treat mental illness. The Igbos of Eastern Nigeria use Ocimum gratissimum for management of baby's cord by keeping the wound sterile. It is used as antifungal, antibacterial and for seasoning of foods.

\section{MATERIALS AND METHODS}

\subsection{Material Preparation}

Aluminium sheets of AAI060 and purity $98.98 \%$ were obtained from Material and Metallurgical Engineering Workshop, Federal University of Technology, Owerri, Nigeria. Each sheet was $0.1 \mathrm{~cm}$ in thickness and mechanically press-cut into coupons of dimension 3 $\mathrm{cm} \times 3 \mathrm{~cm}$. The coupons were descaled using wire brush and degreased in absolute ethanol, dried in acetone, weighed and stored in moisture- free desicator prior to use. The solvents used for extraction of Ocimum gratissimum leaf were $1 \mathrm{M} \mathrm{HCl}$, ethanol and distilled water, respectively. All the solvents used in this study were of analytical reagent grade.

\subsection{Extraction of Plant}

Sample leaves of Ocimum gratissimum were obtained from Ihiagwa market in Owerri, Imo State, Nigeria. The leaf samples were washed and dried under the sunlight and ground to fine powder. $10 \mathrm{~g}$ of leaf extract were extracted with Soxhlet extractor for 3 hours using $1 \mathrm{M}$ $\mathrm{HCl}$, ethanol and distilled water, respectively. After extraction the samples were cooled and filtered. The filtrates obtained were used to prepare inhibitor concentrations between $20 \mathrm{mg} / \mathrm{l}$ and $100 \mathrm{mg} / \mathrm{l}$ in $\mathrm{HCl}$ corrodents.

\subsection{Gravimetric Method}

In weight loss experiment, a hole with diameter $0.5 \mathrm{~cm}$ was drilled in each aluminium coupon so that it could hang freely in solution. The aluminium coupons were suspended in beakers containing $200 \mathrm{ml}$ of test solution maintained at 303--333 K with glass hooks and rods in a thermo-stated water bath. The weight loss was determined by retrieving coupons from test solutions at 3 hours intervals. The coupons after retrieving from test solution were scrubbed with bristle brush under running water, dried in acetone and weighed (Ebenso et al., 2001). The difference in weight was taken as weight loss of aluminium. From weight loss, the inhibition efficiency (\%l.E) of extract and corrosion rate (CR) of aluminium were calculated using equations 1 and 2 , respectively.

$$
\begin{aligned}
& \% \text { I.E }=\left(1-\mathrm{w}_{2} / \mathrm{w}_{1}\right) \times 100 \\
& \text { CR }\left(\mathrm{gh}^{-1} \mathrm{~cm}^{-2}\right)=\Delta \mathrm{w} / \mathrm{AT}
\end{aligned}
$$


Where $w_{1}$, and $w_{2}$ are weight loss of aluminium in absence and presence of inhibitor, respectively. $A$ is area of coupon in $\mathrm{cm}^{2}, T$ is period of immersion in hours and $\Delta \mathrm{W}=\mathrm{w}_{1}-\mathrm{w}_{2}$. The degree of surface coverage was calculated using:

$$
\Theta=1-\left[C_{\text {Rinh }} / C_{\text {RBC }}\right]
$$

Where $\theta$ is surface coverage; $C_{\text {Rinh }}$ is corrosion rate for aluminium in presence of inhibitor, $\mathrm{C}_{\mathrm{RBC}}$ is corrosion rate for aluminium in the absence of inhibitor.

\section{RESULTS AND DISCUSSION}

\subsection{Weight Loss Consideration}

Figs. 1 and 2 represented data of weight loss against concentration for aluminium corrosion in $1 \mathrm{M} \mathrm{HCl}$ in absence and presence of different concentrations of inhibitor, Ocimum gratissimum at $303 \mathrm{k}$ and $333 \mathrm{k}$, respectively. As shown in Figs. 1 and 2, increase in concentration of inhibitor, decreases weight loss of aluminium samples. The result shows that weight loss of aluminium increases as temperature increases as depicted in Fig. 2. The decrease in weight loss as inhibitor concentration increases shows that components of inhibitor retards corrosion of Al samples. The reduction in weight loss of Al samples as inhibitor concentration increases may be attributed to adsorption of inhibitor on surface of $\mathrm{Al}$ and thereafter impede corrosion either by merely blocking reaction sites (anodic and cathodic) or by altering mechanism of anodic and cathodic processes. The result indicates that weight loss of $\mathrm{Al}$ sample using different extracts of inhibitor were in order: $1 \mathrm{M} \mathrm{HCl}>$ $\mathrm{C}_{2} \mathrm{H}_{5} \mathrm{OH}>$ distilled $\mathrm{H}_{2} \mathrm{O}$.

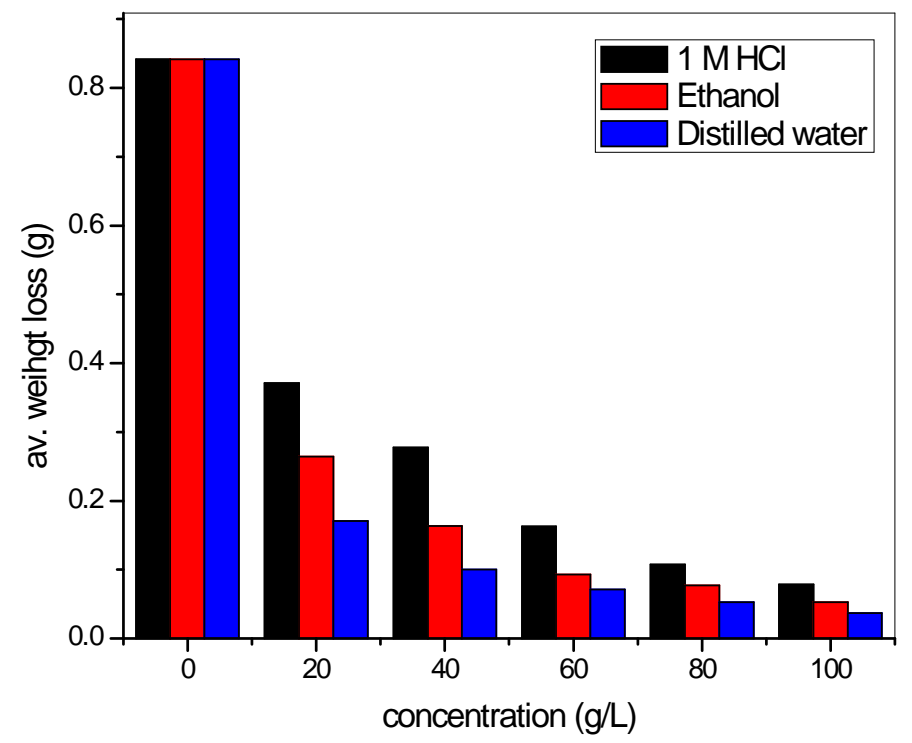

Fig. 1. Variation of weight loss of aluminium in $\mathrm{HCl}$ at various concentrations of $1 \mathrm{M} \mathrm{HCl}$, ethanol and distilled water extracts of Ocimum gratissimum at $303 \mathrm{k}$ 


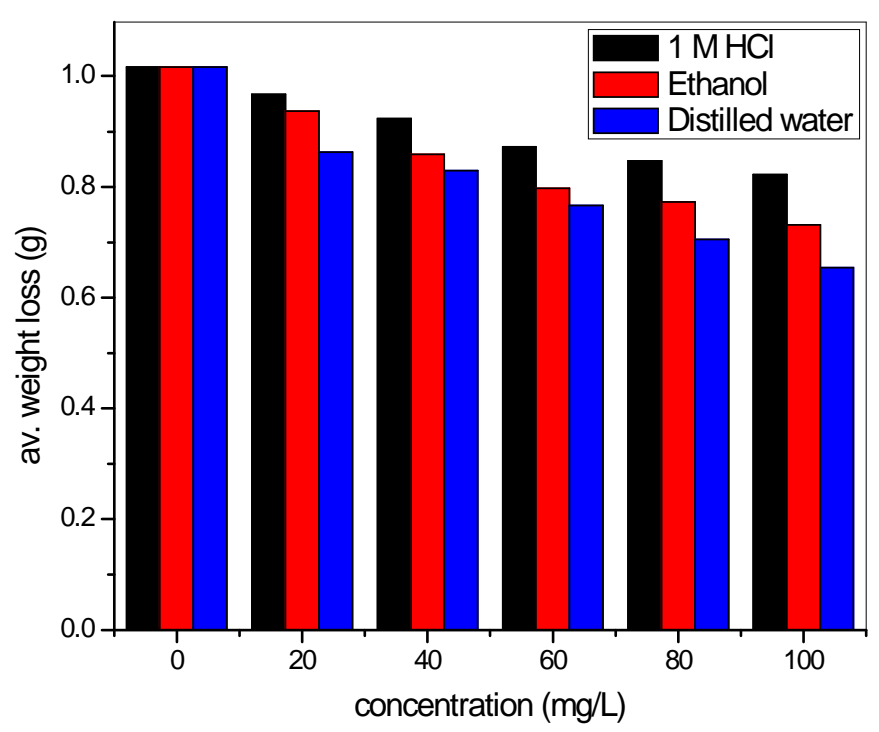

Fig. 2. Variation of weight loss of aluminium in $\mathrm{HCl}$ at various concentrations of $1 \mathrm{M} \mathrm{HCl}$, ethanol and distilled water extracts of Ocimum gratissimum at $333 \mathrm{~K}$

\subsection{Inhibition Efficiency and Surface Coverage}

The percentage of inhibition efficiency (\% I.E) was calculated and represented in tables 1 and 2 at $303 \mathrm{k}$ and $333 \mathrm{k}$, respectively. The result revealed that different extracts of inhibitor inhibits corrosion of Al sample in hydrochloric acid solution. The result indicates that \% I.E increases as concentration of inhibitor increases. A parameter $(\theta)$, which represents part of metal surface covered by inhibitor molecules were calculated for different inhibitor concentrations and represented in tables 1 and 2 . The result shows that surface coverage $(\theta)$ increases as inhibitor concentration increases. The increase in inhibition efficiency and surface coverage as concentration of extracts increases may be due to the presence of complex chemical composition of extracts. The increase in inhibition efficiency with increase in inhibitor concentration suggests that inhibitor molecule were adsorbed at aluminium sample /solution interface where adsorbed species mechanically screen the coated part of aluminium surface from action of corrosive medium.

Table 1. Effect of various inhibitor extracts on $\% \mathrm{I}$.E and $\theta$ for $\mathrm{Al}$ corrosion in $1 \mathrm{M} \mathrm{HCl}$ at $303 \mathrm{k}$

\begin{tabular}{lllllll}
\hline $\begin{array}{l}\text { Concentration } \\
\text { mg/I }\end{array}$ & $\begin{array}{l}\text { 1m HCl extract of } \\
\text { Ocimum } \\
\text { gratissimum }\end{array}$ & $\begin{array}{l}\text { Ethanol extract } \\
\text { of Ocimum } \\
\text { gratissimum }\end{array}$ & $\begin{array}{l}\text { Distilled water extract } \\
\text { of Ocimum } \\
\text { gratissimum }\end{array}$ \\
\hline & \% I.E. & $\boldsymbol{\theta}$ & \% I.E & $\boldsymbol{\theta}$ & \% I.E. & $\boldsymbol{\theta}$ \\
\hline 20.00 & 55.96 & 0.56 & 68.62 & 0.69 & 79.79 & 0.80 \\
40.00 & 67.04 & 0.67 & 80.60 & 0.81 & 88.11 & 0.88 \\
60.00 & 80.70 & 0.81 & 88.96 & 0.89 & 91.53 & 0.92 \\
80.00 & 87.31 & 0.87 & 90.87 & 0.91 & 93.80 & 0.94 \\
100.00 & 90.72 & 0.91 & 93.74 & 0.94 & 95.65 & 0.96 \\
\hline
\end{tabular}


Table 2. Effect of various inhibitor extracts on $\% \mathrm{I} . \mathrm{E}$ and $\theta$ for $\mathrm{Al}$ corrosion in $1 \mathrm{M} \mathrm{HCl}$ at $333 \mathrm{k}$

\begin{tabular}{lllllll}
\hline $\begin{array}{l}\text { Concentration } \\
\text { mg/I }\end{array}$ & \multicolumn{2}{l}{$\begin{array}{l}\text { 1 M HCl extract of } \\
\text { Ocimum gratissimum }\end{array}$} & $\begin{array}{l}\text { Ethanol extract of } \\
\text { Ocimum } \\
\text { gratissimum }\end{array}$ & \multicolumn{2}{l}{$\begin{array}{l}\text { Distilled water } \\
\text { extract of Ocimum } \\
\text { gratissimum }\end{array}$} \\
\cline { 2 - 7 } & \% I.E. & $\boldsymbol{\theta}$ & \% I.E & $\boldsymbol{\theta}$ & $\%$ I.E. & $\boldsymbol{\theta}$ \\
\hline 20.00 & 4.83 & 0.05 & 7.81 & 0.08 & 15.11 & 0.15 \\
40.00 & 9.15 & 0.09 & 15.50 & 0.16 & 18.37 & 0.18 \\
60.00 & 14.16 & 0.14 & 21.55 & 0.22 & 24.60 & 0.25 \\
80.00 & 16.67 & 0.17 & 23.94 & 0.24 & 30.64 & 0.31 \\
100.00 & 19.10 & 0.19 & 28.05 & 0.28 & 35.69 & 0.36 \\
\hline
\end{tabular}

The result shows that distilled water extract exhibited highest inhibition efficiency and surface coverage when compared to values obtained for ethanolic and $1 \mathrm{M} \mathrm{HCl}$ extracts, respectively. The highest inhibition efficiency and surface coverage of distilled water extract may probably be attributed to the presence of more complex chemical composition of distilled water extract. It has been reported (Alinnor and Aneke, 2009) that ethanolic extract of Ocimum gratissimum leaf contains alkaloid, saponins, flavonoids and tannins. The adsorption of these species from extracts on aluminium surface reduces surface area available for corrosion, thereby increasing inhibition efficiency and surface coverage.

Table 2 revealed that \% I.E and $\theta$ decreases at $333 \mathrm{k}$ when compared to values obtained at $303 \mathrm{k}$. The decrease in \% I.E and $\theta$ at $333 \mathrm{k}$ may be explained as a result of increase in average kinetic energy of components of extracts, thus making adsorption between components of extracts and Al surface insufficient to retain the species at binding site. This could lead to desorption or cause species to bounce off surface of aluminium instead of colliding and combining with it. Therefore, increase in temperature may be associated with decrease in stability of components - aluminium surface complex. Report (Odiongenyi et al., 2009) have shown that increase in temperature decreases inhibition efficiency of corrosion of mild steel in $\mathrm{H}_{2} \mathrm{SO}_{4}$ using ethanolic extract of Vernonia amygdalina. Ebenso et al., (2008) working on corrosion of mild steel in $\mathrm{H}_{2} \mathrm{SO}_{4}$ using ethanolic extract of Piper guinensis as green corrosion inhibitor reported decrease in inhibition efficiency at higher temperature. Noor (2007) working on corrosion inhibition of mild steel in acidic solutions with aqueous extract of Fenugreek leaves reported decrease in inhibition efficiency at higher temperature.

Figs. 3 and 4 show plot of inhibition efficiency versus different concentrations of inhibitor at $303 \mathrm{k}$ and $333 \mathrm{k}$, respectively. The result indicates that inhibition efficiency was high at low temperature of $303 \mathrm{k}$ when compared to values obtained at $333 \mathrm{k}$. This observation has been explained earlier in this report. The trend of inhibition efficiency was in order: Distilled $\mathrm{H}_{2} \mathrm{O}>\mathrm{C}_{2} \mathrm{H}_{5} \mathrm{OH}>1 \mathrm{M} \mathrm{HCl}$. 


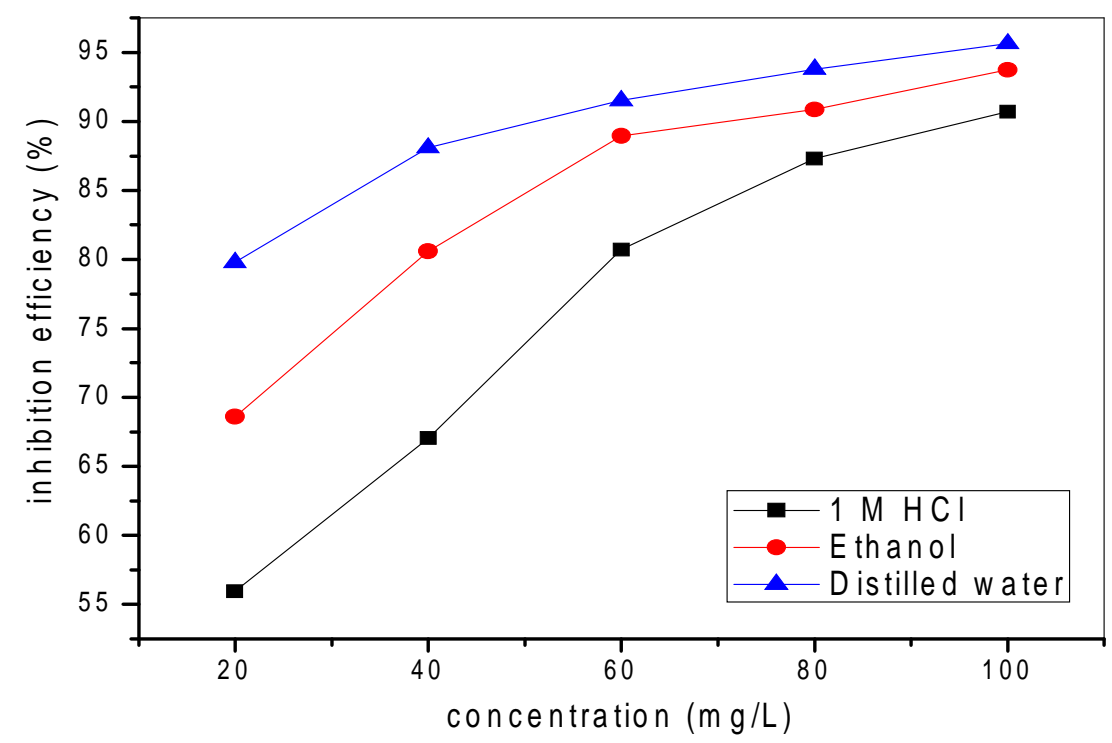

Fig. 3. Variation of inhibition efficiency with concentrations of $1 \mathrm{M} \mathrm{HCl}$, ethanol and distilled water extract of Ocimum gratissimum at $303 \mathrm{~K}$

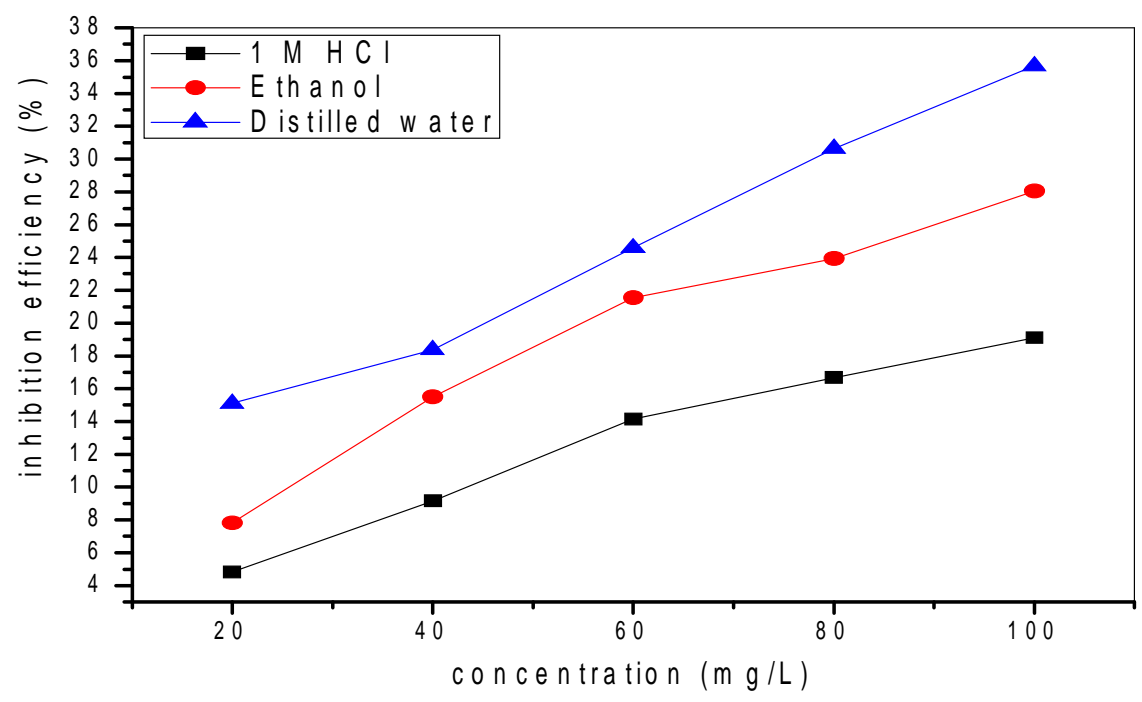

Fig. 4. Variation of inhibition efficiency with concentration of $1 \mathrm{M} \mathrm{HCl}$, ethanol and distilled water extract of Ocimum gratissimum at $333 \mathrm{~K}$

\subsection{Adsorption Consideration}

The adsorption of inhibitor on surface of corroding aluminium sample may be regarded as a substitution process between inhibitor compound in aqueous phase and water molecules adsorbed on aluminium surface:

$$
\operatorname{Inh}_{\mathrm{aq}}+\mathrm{xH}_{2} \mathrm{O}_{\mathrm{ads}} \rightleftharpoons \operatorname{Inh}_{\mathrm{ads}}+\mathrm{xH}_{2} \mathrm{O}_{\mathrm{aq}}
$$


Where $\mathrm{x}$ is size ratio, the number of water molecules displaced by one molecule of organic inhibitor. When the equilibrium as described in Eq (4) is reached, it is possible to obtain different forms of adsorption isotherm.

In the present study Langmuir adsorption isotherm was found to be suitable for the experimental findings and had been used to describe the adsorption characteristic of inhibitor. Langmuir adsorption isotherm is expressed in Eq (5) (Schockry et al., 1998).

$$
\frac{\mathrm{C}_{\text {inh }}}{\Theta}=\frac{1}{\mathrm{k}}+\mathrm{C}_{\text {inh }}
$$

where $C_{\text {inh }}$ is inhibitor concentration, $\mathrm{K}$ is equilibrium constant of adsorption, $\theta$ is degree of surface coverage.

Figs. 5 and 6 show plot of $C_{\text {inh }} / \theta$ versus $C_{\text {inh }}$ at $303 \mathrm{k}$ and $333 \mathrm{k}$, respectively for $1 \mathrm{M} \mathrm{HCl}$, ethanol and distilled water extracts of inhibitor. Figs. 5 and 6 were linear indicating that adsorption of inhibitor is consistent with assumptions of Langmuir adsorption isotherm meaning there is no interaction between adsorbed species.

Adsorption of inhibitor extracts on Al surface was found to follow Flory - Huggins isotherm expressed in Eq (6) (Oguzie et al., 2004):

$$
\log \left(\theta / C_{\text {inh }}\right)=\log K_{c}+x \log (1-\theta)
$$

Where $\theta$ is degree of surface coverage, $C_{\text {inh }}$ is inhibitor concentration, $x$ is number of water molecules replaced by one inhibitor molecule and $\mathrm{K}_{\mathrm{c}}$ is equilibrium constant for adsorption process. Figs. 7, 8 and 9 show Flory - Huggins adsorption isotherm for different extracts of inhibitor using $1 \mathrm{M} \mathrm{HCl}$, ethanol and distilled water at $303 \mathrm{k}$ and $333 \mathrm{k}$, respectively. The calculated values for $x$ and $k_{c}$ for $1 \mathrm{M} \mathrm{HCl}$ extract of inhibitor were 1.00 and 0.007 for $303 \mathrm{k}$ and 0.40 and 0.74 for $333 \mathrm{k}$, respectively. The values for $x$ and $K_{c}$ obtained with ethanol extract of inhibitor were 1.0 and 0.006 for $303 \mathrm{k}$, and 0.30 and 0.63 for $333 \mathrm{k}$, respectively. Also calculated values for $x$ and $k_{c}$ with distilled water extract of inhibitor were 1.51 and 0.005 for $303 \mathrm{k}$, and 0.10 and 0.58 for $333 \mathrm{k}$, respectively. The result indicates that values of $x$ are unity for both $1 \mathrm{M} \mathrm{HCl}$ and ethanol extracts, while distilled water extract of inhibitor is more than unity, indicating that each molecule of inhibitor is attached to one active site on $\mathrm{Al}$ surface.

The values of free energy of adsorption, $\Delta \mathrm{G}_{\text {ads }}$ of $1 \mathrm{M} \mathrm{HCl}$, ethanol and distilled water extracts of inhibitor on Al surface were calculated using Eq (7) (Noor, 2007):

$$
\Delta \mathrm{G}_{\mathrm{ads}}=-2.303 \mathrm{RT} \log (55.5 \mathrm{~K})
$$

Where $R$ is gas constant, $T$ is temperature and $K$ is equilibrium constant of adsorption, given as $K=\theta / 1-\theta$ and 55.5 is concentration of water in solution. The values of $\Delta G_{\text {ads }}$ were negative in $303 \mathrm{k}$ and $333 \mathrm{k}$ indicating spontaneous adsorption of inhibitor on surface of aluminium, and the propose mechanism is physical adsorption $\left(\Delta \mathrm{G}_{\mathrm{ads}}<40 \mathrm{~kJ} / \mathrm{mol}\right)$ (Ebenso, 2004; Bilgic and Sahin, 2001). 


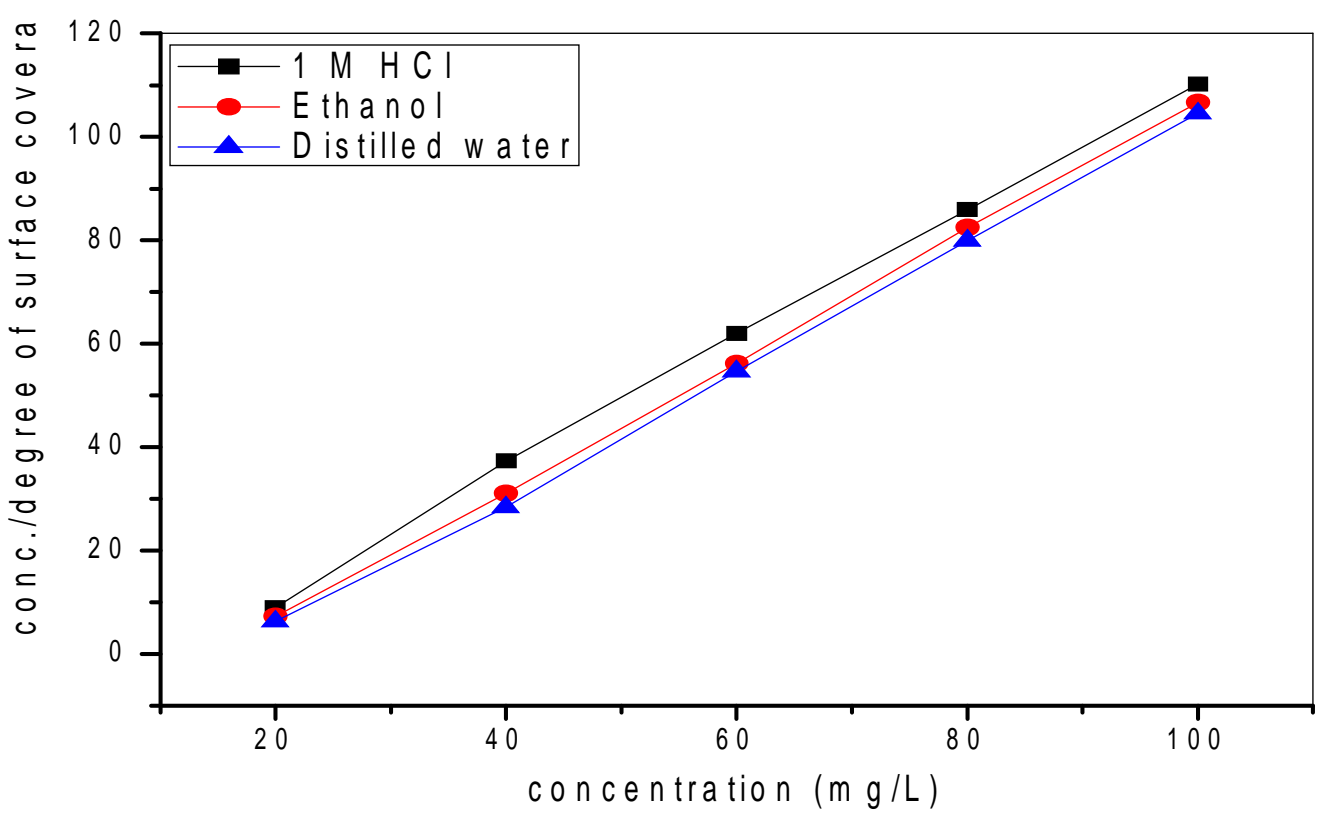

Fig. 5. Langmuir adsorption isotherm at $303 \mathrm{~K}$ for $1 \mathrm{M} \mathrm{HCl}$, ethanol and distilled water Ocimum gratissimum extracts

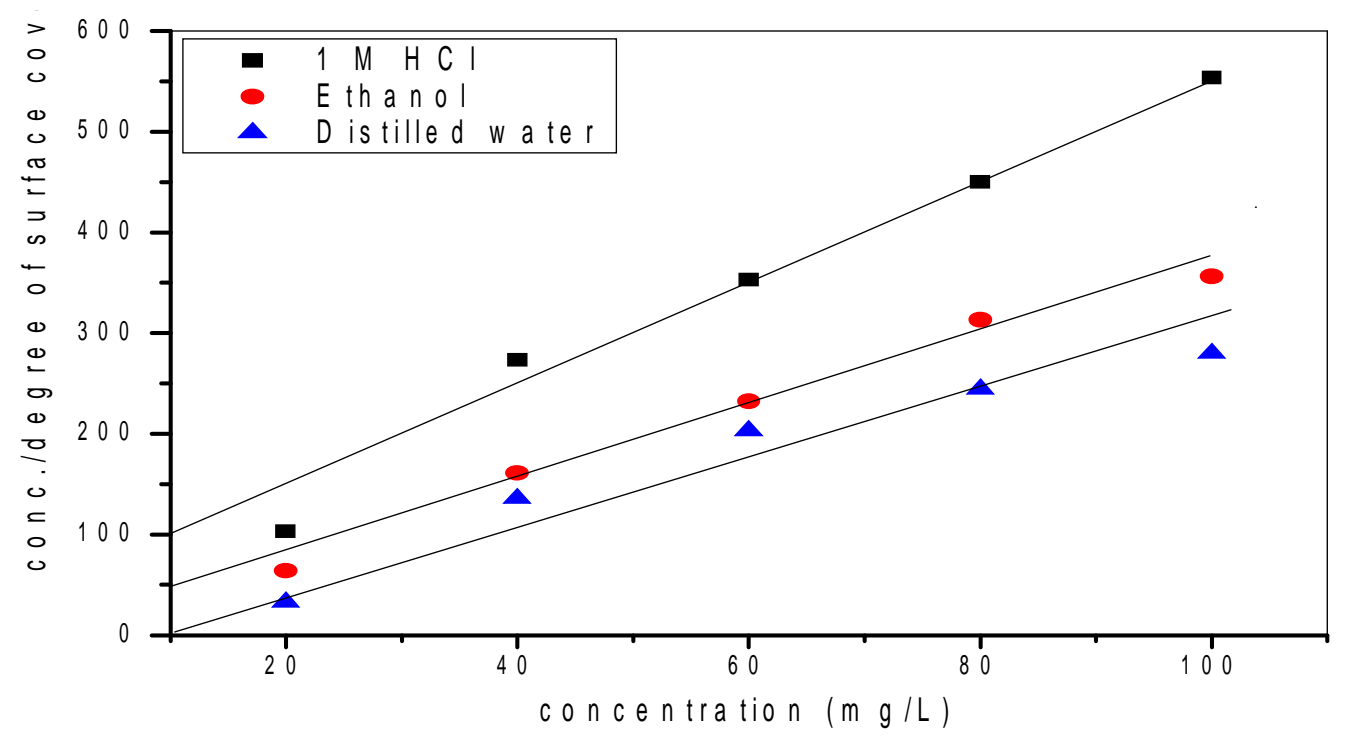

Fig. 6. Langmuir adsorption isotherm at $333 \mathrm{~K}$ for $1 \mathrm{M} \mathrm{HCl}$, ethanol and distilled water Ocimum gratissimum extracts 


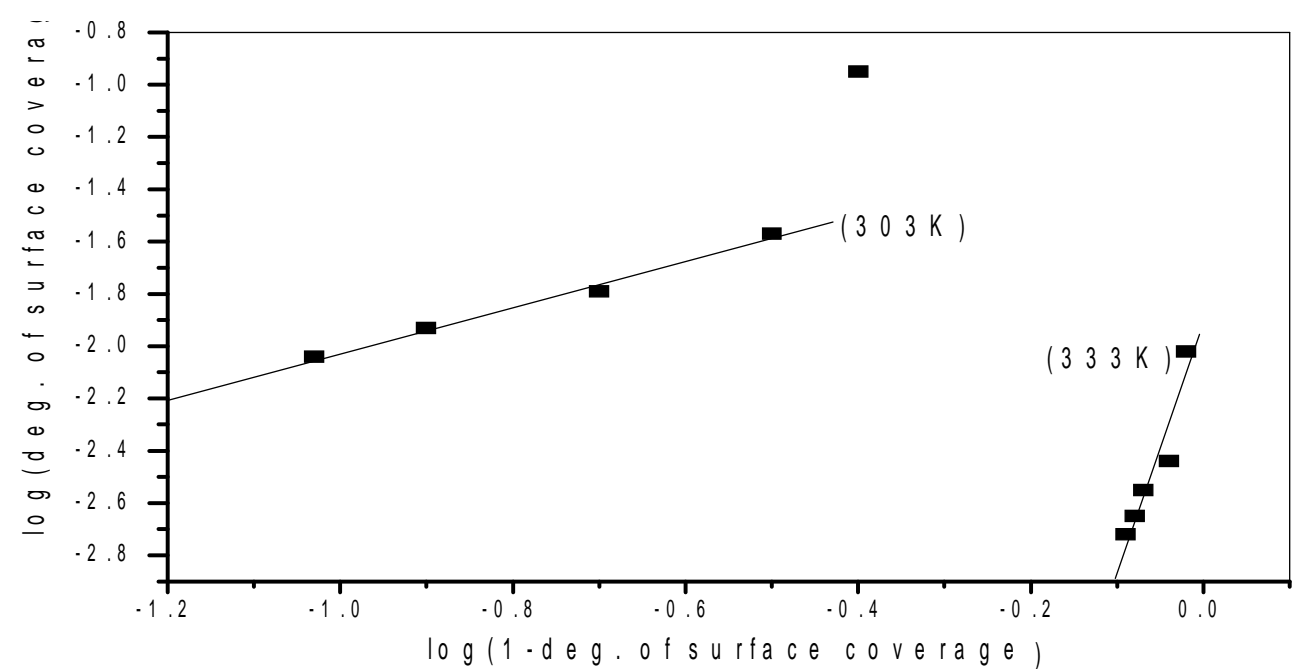

Fig. 7. Flory-Huggins adsorption isotherm at $303 \mathrm{~K}$ and $333 \mathrm{~K}$ for $1 \mathrm{M} \mathrm{HCl} \mathrm{Ocimum}$ gratissimum extract.

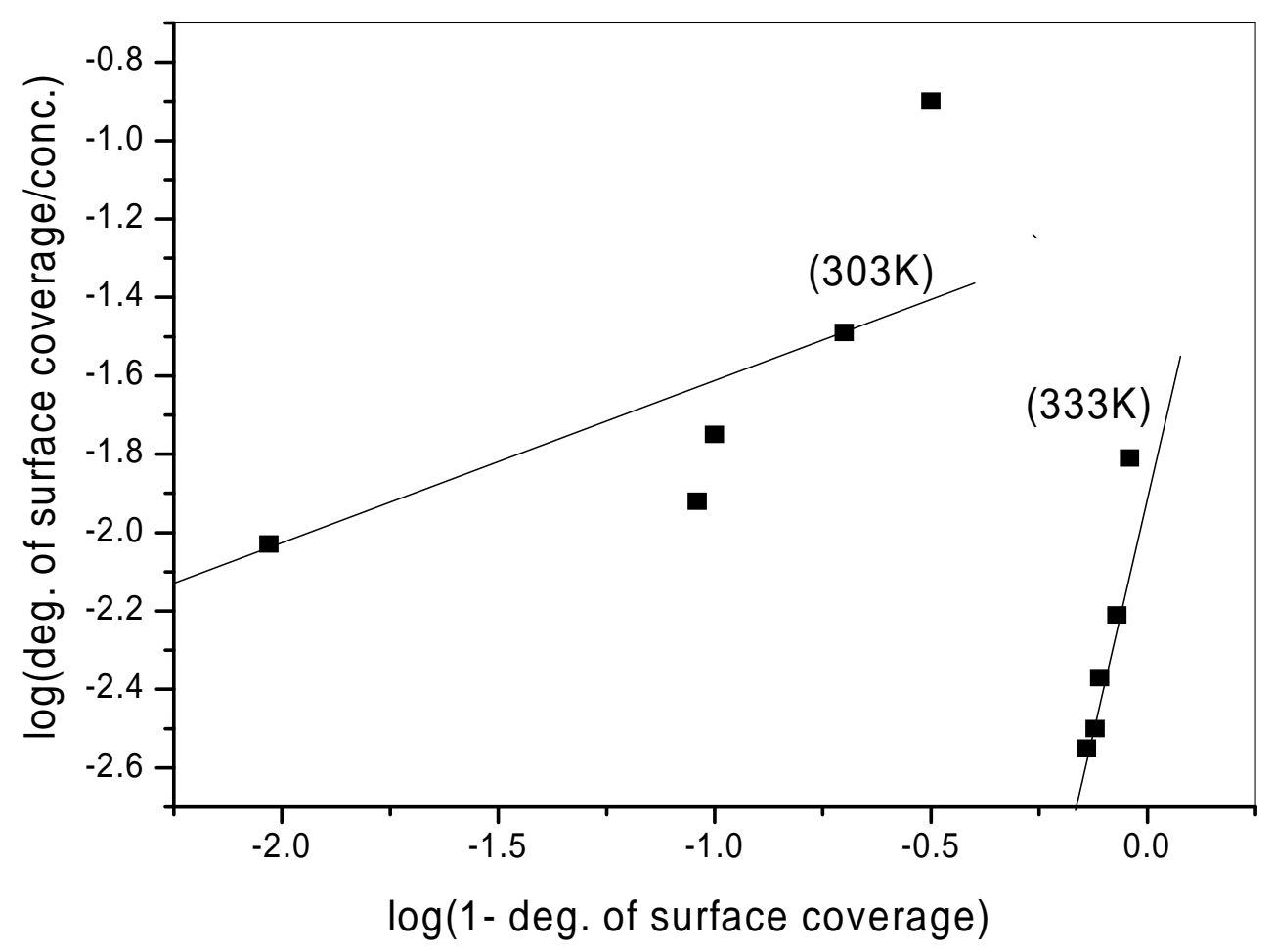

Fig. 8. Flory-Huggins adsorption isotherm at $303 \mathrm{~K}$ and $333 \mathrm{~K}$ for ethanol Ocimum gratissimum extract. 


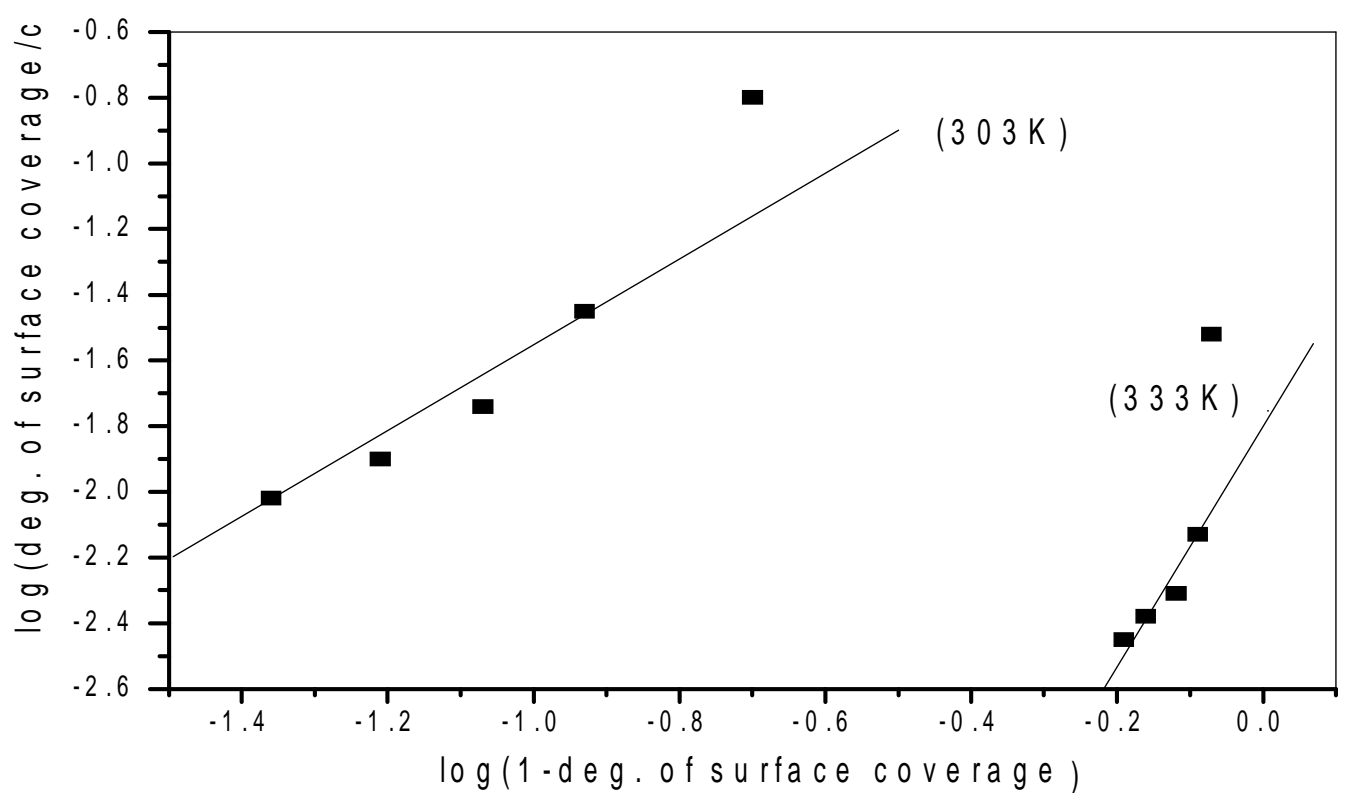

Fig. 9. Flory-Huggins adsorption isotherm at $303 \mathrm{~K}$ and $333 \mathrm{~K}$ for distilled water Ocimum gratissimum extract.

\subsection{Effect of Temperature}

The influence of temperature on weight loss of $\mathrm{Al}$ sample in $1 \mathrm{M} \mathrm{HCl}$ in presence and absence of different concentrations of inhibitor has been depicted in figs. 1 and 2 . The increase in temperature decreases inhibition efficiency and degree of surface coverage. The reasons for this observation have been explained earlier in this study. In order to calculate apparent activation energy, $E_{a}$, for corrosion reaction of $A l$ in absence and presence of various concentrations of inhibitor, the Arrhenius equation was used:

$$
\log \left(\ell_{2} / \ell_{1}\right)=E_{a} / 2.303 R\left[1 / T_{1}-1 / T_{2}\right]
$$

Where $\ell_{1}$ and $\ell_{2}$ are corrosion rates at temperatures $T_{1}$ and $T_{2}$, respectively, and $R$ is gas constant.

The heat of adsorption $\left(Q_{a d s}\right)$ of inhibitor on surface of $A l$ was evaluated using equation (9) (Bhajiwala and Vashi, 2001).

$$
Q_{\text {ads }}=2.303 R\left[\log \left(\theta_{2} / 1-\theta_{2}\right)-\log \left(\theta_{1} / 1-\theta_{1}\right)\right] \times T_{1} T_{2} / T_{2}-T_{1}
$$

Where $\theta_{1}$ and $\theta_{2}$ are degree of surface coverage at temperatures $T_{1}$ and $T_{2}$. The calculated values of apparent activation energy $E_{a}$, and heat of adsorption, $Q_{a d s}$ of different inhibitor extracts are shown in Tables 3, 4 and 5, respectively. 
Table 3. Values of thermodynamic parameters for adsorption of distilled water extract of Ocimum gratissimum on surface of aluminium in $1 \mathrm{M} \mathrm{HCl}$

\begin{tabular}{lllll}
\hline $\begin{array}{l}\text { Concentration of } \\
\text { Ocimum gratissimum } \\
\text { (mg /I) }\end{array}$ & $\begin{array}{l}\text { Activation } \\
\text { energy, } \mathrm{E}_{\mathrm{a}} \\
(\mathrm{KJ} / \mathbf{m o l})\end{array}$ & $\begin{array}{l}\text { Heat of } \\
\text { adsorption } \\
\mathbf{Q}_{\text {ads }} \\
\mathbf{K J} / \mathbf{m o l})\end{array}$ & $\begin{array}{l}\text { Free energy } \\
\text { change } \Delta \mathbf{G}_{\text {ads }} \\
(\mathrm{KJ} / \mathbf{m o l} \text { of } \\
\text { adsorption at } \\
\mathbf{3 0 3 k}\end{array}$ & $\begin{array}{l}\text { Free energy } \\
\text { change, } \Delta \mathbf{G}_{\text {ads }} \\
(\mathrm{KJ} / \mathbf{m o l} \text { of } \\
\text { adsorption at } \\
\mathbf{3 3 3 k}\end{array}$ \\
\hline Blank & & - & - & - \\
20.00 & 5.24 & -86.68 & -13.58 & -5.77 \\
40.00 & 45.02 & -97.72 & -15.17 & -6.36 \\
60.00 & 58.64 & -97.89 & -16.12 & -7.30 \\
80.00 & 65.82 & -98.82 & -16.96 & -8.06 \\
100.00 & 72.18 & -102.90 & -17.91 & -8.64 \\
\hline
\end{tabular}

Table 4. Values of thermodynamic parameters for adsorption of ethanol extract of Ocimum gratissimum on surface of aluminium in $1 \mathrm{M} \mathrm{HCl}$

\begin{tabular}{lllll}
\hline $\begin{array}{l}\text { Concentration of } \\
\text { Ocimum gratissimum } \\
\text { (mg /I) }\end{array}$ & $\begin{array}{l}\text { Activation } \\
\text { energy, } E_{a} \\
(\mathrm{KJ} / \mathbf{m o l})\end{array}$ & $\begin{array}{l}\text { Heat of } \\
\text { adsorption } \\
\mathbf{Q}_{\mathrm{ads}}(\mathrm{KJ} / \mathbf{m o l})\end{array}$ & $\begin{array}{l}\text { Free energy } \\
\mathbf{C h a n g e} \Delta \mathbf{G}_{\text {ads }} \\
(\mathrm{KJ} / \mathbf{m o l}) \text { of } \\
\text { adsorption at } \\
\mathbf{3 0 3 k}\end{array}$ & $\begin{array}{l}\text { Free energy } \\
\text { change, } \Delta \mathbf{G}_{\text {ads }} \\
(\mathrm{KJ} / \mathbf{m o l}) \text { of } \\
\text { adsorption at } \\
\mathbf{3 3 3 k}\end{array}$ \\
\hline Blank & & - & - & - \\
20.00 & 5.24 & -71.22 & -12.09 & -3.90 \\
40.00 & 35.12 & -87.25 & -13.71 & -5.85 \\
60.00 & 46.02 & -94.50 & -15.38 & -6.86 \\
80.00 & 59.58 & -96.60 & -15.91 & -7.21 \\
100.00 & 63.99 & -102.04 & -16.94 & -7.75 \\
\hline
\end{tabular}

Table 5. Values of thermodynamic parameters for adsorption of $1 \mathrm{M} \mathrm{HCl} \mathrm{extract} \mathrm{of}$ Ocimum gratissimum on surface of aluminium in $1 \mathrm{M} \mathrm{HCl}$

\begin{tabular}{|c|c|c|c|c|}
\hline $\begin{array}{l}\text { Concentration of } \\
\text { Ocimum } \\
\text { gratissimum } \\
\text { (mg /l) }\end{array}$ & $\begin{array}{l}\text { Activation } \\
\text { energy, } E_{a} \\
(\mathrm{KJ} / \mathrm{mol})\end{array}$ & $\begin{array}{l}\text { Heat of } \\
\text { adsorption } \\
Q_{\text {ads }}(\mathrm{KJ} / \mathrm{mol})\end{array}$ & $\begin{array}{l}\text { Free energy } \\
\text { Change } \Delta G_{\text {ads }} \\
\text { (KJ/mol) of } \\
\text { adsorption at } \\
303 \mathrm{~K}\end{array}$ & $\begin{array}{l}\text { Free energy } \\
\text { change, } \Delta G_{\text {ads }} \\
(\mathrm{KJ} / \mathrm{mol}) \text { OF } \\
\text { adsorption at } \\
333 \mathrm{k}\end{array}$ \\
\hline Black & 5.24 & - & - & - \\
\hline 20.00 & 26.60 & -84.04 & -10.72 & -2.61 \\
\hline 40.00 & 33.34 & -84.06 & -11.89 & -4.34 \\
\hline 60.00 & 46.60 & -90.07 & -13.72 & -5.58 \\
\hline 80.00 & 57.40 & -90.41 & -14.98 & -6.07 \\
\hline 100.00 & 65.25 & -98.95 & -15.86 & -6.48 \\
\hline
\end{tabular}

The results shown in tables 3,4 and 5 of different inhibitor extract indicates that apparent activation energy $E_{a}$, increases as inhibitor concentration increases. Activation energy of distilled water extract ranged between 45.02 to $79.90 \mathrm{KJ} / \mathrm{mol}$. While the activation energies of ethanol and $1 \mathrm{M} \mathrm{HCl}$ extracts of inhibitor ranged between 35.12 to $72.93 \mathrm{KJ} / \mathrm{mol}$ and 26.60 to $65.25 \mathrm{KJ} / \mathrm{mol}$, respectively. Since corrosion primarily occurs at surface sites free of 
adsorbed inhibitor, the higher $E_{a}$ values in inhibited solutions imply that extracts mechanically screen the active sites of Al surface thereby decreasing the surface area available for corrosion. The order of apparent activation energy, $E_{a}$ of different extracts was in order: distilled $\mathrm{H}_{2} \mathrm{O}>\mathrm{C}_{2} \mathrm{H}_{5} \mathrm{OH}>1 \mathrm{M} \mathrm{HCl}$.

The heat of adsorption, $Q_{a d s}$ were all negative and ranged from -86.68 to $-102.90 \mathrm{KJ} / \mathrm{mol}$ for distilled water extract, while ethanol and $1 \mathrm{M} \mathrm{HCl}$ extracts ranged from -71.22 to -102.04 $\mathrm{KJ} / \mathrm{mol}$ and -- 84.04 to -- $98.95 \mathrm{KJ} / \mathrm{mol}$, respectively. The negative $Q_{\text {ads }}$ values indicate that adsorption and hence inhibition efficiency decreases as temperature increases, supporting the earlier proposed physisorption mechanism (Bhajiwala and Vashi, 2001).

\section{CONCLUSION}

This study indicates that extract of Ocimum gratissimum inhibits Al surface in presence of 1 $\mathrm{M} \mathrm{HCl}$. The corrosion process is inhibited by adsorption of extracts on aluminium surface. Inhibition efficiency increase with increase in inhibitor concentrations. The result of the analysis shows that inhibition efficiency and degree of surface coverage decreases as temperature increases. Activation energies of different extracts increase as concentration of inhibitor increases. The negative values of $\Delta \mathrm{G}_{\mathrm{ads}}$ shows that adsorption of inhibitor on surface of aluminium is spontaneous. The adsorption behaviour was approximated by Langmuir and Flory - Huggins isotherms. The trend of inhibition efficiency of different extracts was in order: Distilled $\mathrm{H}_{2} \mathrm{O}>\mathrm{C}_{2} \mathrm{H}_{5} \mathrm{OH}>1 \mathrm{M} \mathrm{HCl}$.

\section{ACKNOWLEDGEMENT}

The authors are grateful to Miss Cynthia Nwigwe for her technical assistance in performing some measurements.

\section{COMPETING INTERESTS}

Authors have declared that no competing interest exist

\section{REFERENCES}

Abdel-Gaber, A.M., Khamis, E., Abo-EIDahab, H., Adeel Sh. (2008). Inhibition of aluminium corrosion in alkaline solutions using natural compound. Mater. Chem. Phys, 109, 297- 305.

Abiola, O.K., Oforka, N.C., Ebenso, E.E., Nwinuka, N.M. (2007). Eco- friendly corrosion inhibitor: Inhibitive action of Delonix regia extract for the corrosion of aluminium in acidic medium. Anti - Corrosion methods and material, 54, $219-224$.

Alinnor, I.J., Aneke, J.N. (2009). Study of Phytochemical and antibacterial Evaluation of crude extracts of Ocimum gratissimum. Int. J. Chem. Sci, 2(2), 286 -292.

Aytac, A., .Ozmen, U., Kabasakaloglu, M. (2005). Investigation of some Schiff bases as acidic corrosion of alloy AA3102. Mater. Chem. Phys., 89(1), 176-181.

Bhajiwala, H.M., Vashi, R.T. (2001). Ethanolamine, diethanolamine and triethanolamine as corrosion inhibitors for zinc in binary acid mixture $\left(\mathrm{HNO}_{3}+\mathrm{H}_{3} \mathrm{PO}_{4}\right)$. Bull. Electochem, 17, 411-448.

Bilgic, S., Sahin, M. (2001). The corrosion inhibition of austenitic chromium - nickel steel in $\mathrm{H}_{2} \mathrm{SO}_{4}$ by 2 - butyn -1-0l. Mater. Chem. Phys., 70, 290-295. 
Cotton, F.B., Wilkinson, G. (1972). Advanced Inorganic Chemistry. A comprehensives text. $3^{\text {rd }}$ ed. John Wiley and Sons. Inc, New York.

Ebenso, E.E., Okafor, P.C., Offiong, O.E., Ita, B.I., Ibok, U.J., Ekpe, U.J. (2001). Comparative investigation into the kinetics and corrosion inhibition of aluminium alloy AA1060 in acidic medium, Bull. of Electrochemistry, 17(10), 459-464.

Ebenso, E.E. (2004). Effect of methyl red and halide ions on the corrosion inhibition of aluminium in $\mathrm{H}_{2} \mathrm{SO}_{4}$ Part 2. Bull. Electrochem, 20, 551- 559.

Ebenso, E.E., Eddy, N.O., Odiongenyi, A.O. (2008). Corrosion inhibitive properties and adsorption behaviour of ethanol extract of Piper guinensis as a green corrosion inhibitor for mild steel in $\mathrm{H}_{2} \mathrm{SO}_{4}$. African J. Pure and Appl. Chemistry, 2(11), 107 -115

Eddy, N.O., Ebenso, E.E. (2008). Adsorption and inhibitive properties of ethanol extract of Musa sapientum peels as a green corrosion in acidic medium. African J. Pure Appl. Chem., 2(6), 46-54.

Elewady, G.Y., El-Said, I.A; Fouda, A.S. (2008). Effect of anions on the corrosion inhibition of aluminium in $\mathrm{HCl}$ using ethyl trimethyl ammonium bromide as cationic inhibitor. Int. J. Electrochem. Sci., 3, 644-655.

Kliskic, M., J. Radoservic, J., Gudic, S., Katalinic, V. (2000). Aqueous extract of Rosemarius officinalis L. as inhibitor of Al-mg alloy corrosion in chloride solution. J. Appl. Electrochem, 30, 823-830.

Madkour, L.M., Issa, R.M; El-Ghrabawy, I.M. (1999). Kinetics of substituted bis -and monoazo dyes as corrosion inhibitors for aluminium in hydrochloric acid and sodium hydroxide. J. Chemical Research, 8, $408-409$.

Moussa, M.N., Fouda, A.S., Taha, A.T., Elnenaa, A. (1998). Some thiosemicarbazide derivatives as corrosion inhibitors for aluminium in sodium hydroxide solution. Bulletin of the Korean Chemical Society, 9, 192-195.

Noor, E.A. (2007). Temperature effects on the corrosion inhibition of mild steel in acidic solutions by aqueous extract of Fenugreek leaves. Int. J. Electrochem. Sci., 2, 9961017.

Odiongenyi, A.O., Odoemelam, S.A., Eddy, N.O. (2009). Corrosion inhibition and adsorption properties of ethanol extract of Vernonia amygadalina for the corrosion of mild steel in $\mathrm{H}_{2} \mathrm{SO}_{4}$. Portugaline Electrochimica Acta., 2(1), 34-45.

Oguzie, E.E., Okolue, B.N., Ebenso, E.E; Onuoha, G.N; Onuchukwu, A.I. (2004). Evaluation of the inhibitory effect of methylene blue dye on the corrosion of aluminium in hydrochloric acid. Mater. Chem. Phys., 87, 394-401.

Oguzie, E.E. (2005). Inhibition of acid corrosion of mild steel by Telfaria occidentalis extract. Pigment and Resin Technol., 34, 321-326.

Schockry, H., Yuasa, M., Sekine, I., Issa, R.M., El-baradie, H.Y., Gomma, G.K. (1998). Corrosion inhibition of mild steel by Schiff base compounds in various aqueous solution. Part I. Corros. Sci., 40, 2173-2186.

Umoren, S.A., Ebenso, E.E. (2008). Studies of anit-corrosion effect of Raphia hookeri exudates gum-halide mixtures for aluminium corrosion in acidic medium. Pigment and Resin Technol., 37, 173-182.

USDA. (2008). (United States Department of Agriculture) Agricultural Research Service.

(c) 2012 Alinnor and Ejikeme; This is an Open Access article distributed under the terms of the Creative Commons Attribution License (http://creativecommons.org/licenses/by/3.0), which permits unrestricted use, distribution, and reproduction in any medium, provided the original work is properly cited.

Peer-review history:

The peer review history for this paper can be accessed here: http://www.sciencedomain.org/review-history.php?iid=149\&id=16\&aid=688. 